University of Nebraska - Lincoln

DigitalCommons@University of Nebraska - Lincoln

\title{
BLOOD HOMOCYSTEINE LEVELS IN THE NATIONAL HEALTH AND NUTRITION EXAMINATION SURVEY (NHANES III) IN THE UNITED STATES: PRELIMINARY FINDINGS BY AGE AND SEX
}

\author{
Irwin H. Rosenberg \\ Jean Mayer USDA Human Nutrition Research Center on Aging \\ Jacob Selhub \\ Jean Mayer USDA Human Nutrition Research Center on Aging \\ Paul F. Jacques \\ Jean Mayer USDA Human Nutrition Research Center on Aging \\ Barbara A. Bowman \\ Centers for Disease Control and Prevention, Atlanta, GA \\ Elaine W. Gunter \\ Centers for Disease Control and Prevention, Atlanta, GA \\ See next page for additional authors \\ Follow this and additional works at: https://digitalcommons.unl.edu/publichealthresources \\ Part of the Public Health Commons
}

Rosenberg, Irwin H.; Selhub, Jacob; Jacques, Paul F.; Bowman, Barbara A.; Gunter, Elaine W.; Johnson, Clifford L.; and Murphy, R. S., "BLOOD HOMOCYSTEINE LEVELS IN THE NATIONAL HEALTH AND NUTRITION EXAMINATION SURVEY (NHANES III) IN THE UNITED STATES: PRELIMINARY FINDINGS BY AGE AND SEX" (1997). Public Health Resources. 207.

https://digitalcommons.unl.edu/publichealthresources/207

This Article is brought to you for free and open access by the Public Health Resources at DigitalCommons@University of Nebraska - Lincoln. It has been accepted for inclusion in Public Health Resources by an authorized administrator of DigitalCommons@University of Nebraska - Lincoln. 


\section{Authors}

Irwin H. Rosenberg, Jacob Selhub, Paul F. Jacques, Barbara A. Bowman, Elaine W. Gunter, Clifford L. Johnson, and R. S. Murphy 


\section{HOMOCYSTEINE \\ METABOLISM: FROM \\ BASIC SCIENCE TO \\ CLINICAL MEDICINE}

Editors

Ian Graham, MD

THE ADELAIDE HOSPITAL

TRINITY COLLEGE

DUBLIN

IRELAND

Helga Refsum, MD

UNIVERSITY OF BERGEN

DEPARTMENT OF CLINICAL BIOLOGY

BERGEN

NORWAY

Irwin H. Rosenberg, MD

JEAN MAYER USDA HUMAN NUTRITION RESEARCH

CENTER ON AGING AT TUFTS UNIVERSITY

BOSTON, MA

USA

Per Magne Ueland, MD

UNIVERSITY OF BERGEN

DEPARTMENT OF CLINICAL BIOLOGY

BERGEN

NORWAY

Scientific Editor:

Jill M. Shuman, MS, RD, ELS

TUFTS UNIVERSITY SCHOOL OF

NUTRITION SCIENCE AND POLICY MEDFORD, MA

$$
\text { USA }
$$

Kluwer Academic Publishers

BOSTON DORDRECHT LONDON 
Irwin H. Rosenberg

Jean Mayer USDA Human Nutrition Research

Center on Aging

Tufts University

Boston, MA, USA

Jacob Selhub

Jean Mayer USDA Human Nutrition Research

Center on Aging

Tufts University

Boston, MA, USA

Paul F. Jacques

Jean Mayer USDA Human Nutrition Research

Center on Aging

Tufts University

Boston, MA, USA

Barbara A. Bowman

Centers for Disease Control and Prevention

Atlanta, GA, USA

Elaine W. Gunter

Centers for Disease Control and Prevention

Atlanta, GA, USA

Clifford L. Johnson

National Center for Health Statistics

Washington, DC, USA

R.S. Murphy

National Center for Health Statistics

Washington, DC 


\section{BLOOD HOMOCYSTEINE LEVELS}

IN THE NATIONAL HEALTH AND

NUTRITION EXAMINATION SURVEY

(NHANES III) IN THE UNITED STATES:

PRELIMINARY FINDINGS BY AGE

AND SEX

Irwin H. Rosenberg, Jacob Selhub, Paul F. Jacques, Barbara A. Bowman, Elaine W. Gunter, Clifford L. Johnson, and R.S. Murphy

\section{Introduction}

Evidence from scores of observational studies from many parts of the world have demonstrated an association between elevated blood total homocysteine levels and the risk of cardiovascular disease, peripheral vascular disease, and stroke $[1,2]$. These conditions are more prevalent in males than in females in virtually all populations studied, and their prevalence increases with advancing age. A much smaller body of data exists that describes an increasing tendency to higher homocysteine levels with increasing age.

There have been no previous reports of blood homocysteine levels measured in a cross-sectional sample throughout the age spectrum from childhood through the elderly. However, the Third National Health and Nutrition Examination Survey (NHANES III) in the United States provides such a representative sample. We present here the results of the homocysteine analyses on 10,000 samples of serum representing ages 12 years to 100 years in both males and females.

\section{The Third National Health and}

Nutrition Examination Survey

(NHANES III): 1988-1994

The U.S. National Center for Health Statistics has conducted six health examination surveys of the U.S. population since 1960 , and has recently completed NHANES III [3]. The surveys are designed to obtain nationally representative information about the health and nutrition status of American populations through interviews and direct physical examinations. Physical examinations are employed because the information collected either cannot be furnished or is not available in a standardized manner through interviews with the people themselves or through records maintained by health professionals who provide their medical care.

The goals of NHANES III are: (1) to estimate the national prevalence of selected disease and risk factors, (2) to provide national population reference distributions of selected health parameters, (3) to document and investigate reasons for secular trends and selected diseases and risk factors, (4) to contribute to an understanding of disease etiology, and (5) to investigate the natural history of selected diseases.

The eligible population for this NHANES III is the U.S. civilian noninstitutionalized population ages 2 months or older [4]. The sample design utilizes a stratified multistage probability sample of counties, blocks, and persons randomly selected from households. The periods from 1988-1991 and 1991-1994 each constitute national samples of the U.S. population as well as all six years combined. Eighty-one counties were selected from 26 states, from which 
approximately 40,000 persons were selected and 30,000 agreed to participate. In the period from 1988-1991 (Phase I), 20,277 persons were selected for the sample. Of those, 17,464 were interviewed and 15,630 (77\%) have participated in the Examination. Precise estimates of health characteristics are needed for specific subgroups of the population (children $<5$ years, persons 60 years and older, black Americans and Mexican Americans) and these groups

TABLE 25-1. Sampling

subdomains by race and age: NHANES III

\begin{tabular}{lll}
\hline African-American & White and all other & $\begin{array}{l}\text { Mexican- } \\
\text { American }\end{array}$ \\
\hline 2-35 months & $\begin{array}{l}2-11 \text { months } \\
12-35 \text { months }\end{array}$ & $2-35$ months \\
& $3-5$ years & $3-5$ years \\
3-5 years & $6-11$ years & $6-11$ years \\
6-11 years & $12-19$ years & $12-19$ years \\
$12-19$ years & $20-29$ years & $20-29$ years \\
$20-39$ years & $30-39$ years & \\
& $40-49$ years & $40-49$ years \\
$40-59$ years & $50-59$ years & \\
& $60-69$ years & 60 years and \\
60 years and over & $70-79$ years & \\
& 80 years and over
\end{tabular}

TABLE 25-2. Diseases studied in NHANES III

\begin{tabular}{ll}
\hline $\begin{array}{l}\text { heart disease } \\
\begin{array}{l}\text { asthma, chronic } \\
\text { bronchitis, emphysema }\end{array}\end{array}$ & $\begin{array}{c}\text { dental caries and periodontal } \\
\text { disease } \\
\text { allergies }\end{array}$ \\
$\begin{array}{l}\text { diabetes } \\
\text { kidney disease and other } \\
\text { urologic disorders }\end{array}$ & $\begin{array}{l}\text { depression } \\
\text { hearing loss }\end{array}$ \\
$\begin{array}{l}\text { gall bladder disease } \\
\text { osteoporosis } \\
\text { arthritis }\end{array}$ & $\begin{array}{l}\text { vision problems } \\
\text { infectious disease }\end{array}$ \\
\hline
\end{tabular}

TABLE 25-3. Nutrition assessment in NHANES III

Dietary/nutrient intake

Anthropometric measurments

Nutritional biochemistries and hematologic tests

Physical examination

Interview are being selected in greater numbers than would have occurred without oversampling.

NHANES III data collection began in the fall of 1988 and was completed in the fall of 1994 . Over the 6-year survey, more than 36,000 persons were interviewed, and more than 30,000 completed a standardized detailed physical examination in specially equipped mobile examination centers that traversed the country. The survey was conducted in two consecutive 3-year phases and designed so that each phase was a national probability sample. Table $25-1$ presents the sampling scheme for NHANES III, which was designed to enroll a minimum of 560 individuals in each of the 52 sex, race, and age strata. Serum samples for the determination of homocysteine were derived from Phase II of this survey. We have already received all samples for participants aged 12 and older, and measured homocysteine concentrations on samples from 1,981 men and 2,401 women to date. When completed, we anticipate that homocysteine values will be available for greater than 10,000 survey participants ages 12 through 100 years. We also plan to determine homocysteine levels on approximately 3,000 samples from participants aged 3 to 11 years.

The data collected in this survey will be used to estimate the prevalence of major diseases and nutrition disorders, as well as potential risk factors. NHANES III data will also be the basis for national standards that measure height, weight, and blood pressure. Data from NHANES III will be used in epidemiologic and health science research to direct and design health programs and services and expand the health knowledge for the nation.

As in the past Health Examination Surveys, data from NHANES III will describe the prevalence of chronic conditions in the population, data on previously undiagnosed conditions, and those known to and reported by the survey respondent. The diseases

TABLE 25-4. Nutritional biochemistry analysis in NHANES III

Retionl and retinyl esters

Carotene profile

Selenium

Calcium, total and ionized

Vitamin A, vitamin C, vitamin D, vitamin $\mathrm{E}$

Serum iron: total iron binding capacity

Serum ferritin and protoporphyrin

Serum and red cell folate

Serum homocysteine

Serum methylmalonic acid

Vitamin B12 
and medical conditions to be studied are included in table 25-2. Table 25-3 lists the methods and procedures used to assess nutritional status. Table 25-4 lists the nutritional biochemical measures used to assess micronutrient status in this survey.

\section{Serum Homocysteine in NHANES III}

Having serum homocysteine analyses available from a large representative sample of U.S. population $(n=$ 15,000 , age $\geq$ than 3 ) with an oversampling for elderly and minority groups, a complete physical examination, hematology, serum and urinary biochemical data, anthropometry/body composition, dietary data, and information on supplement use, etc., provides a remarkable opportunity for analysis. Blood was drawn on participants whose fasting status was variable but recorded. Whole blood was held at room temperature for 30-60 minutes prior to centrifugation. Sera were separated and frozen at $-20^{\circ} \mathrm{C}$ and transferred to the Centers for Disease Control and Prevention's central laboratory for priority analyses. Some samples went through numerous freeze cycles. After priority analyses were complete, the surplus sera were held at $-70^{\circ} \mathrm{C}$ for periods ranging from eight months to 3 years before they were analyzed for homocysteine.

Homocysteine measurements were carried out at the USDA Human Nutrition Research Center on Aging using the method of Araki and Sato [5]. The preliminary results presented here are based on a sample of 1,981 males and 2,401 females aged 12102 years. The mean age for both men and women was 43.8 years. The age-adjusted geometric mean homocysteine concentrations for men and women were 9.8 and $8.0 \mu \mathrm{mol} / \mathrm{L}$ respectively (fig. 25-1). Homocysteine concentrations increased continuously with age for men and women, and were greater for men at all ages (fig. 25-2). In men, geometric mean concentrations increased by $63 \%$ across the age range presented here, from $7.7 \mu \mathrm{mol} / \mathrm{L}$ at ages $12-19$ years to $12.4 \mu \mathrm{mol} / \mathrm{L}$ in the $85+$-year-old age group. For women, geometric mean homocysteine concentrations increased $75 \%$, from 6.4 to $11.2 \mu \mathrm{mol} / \mathrm{L}$ across the ages considered here.

There was a significant age-sex interaction $(p<$ 0.001 ), indicating that the age relations differed in men and women. The age-related increase in

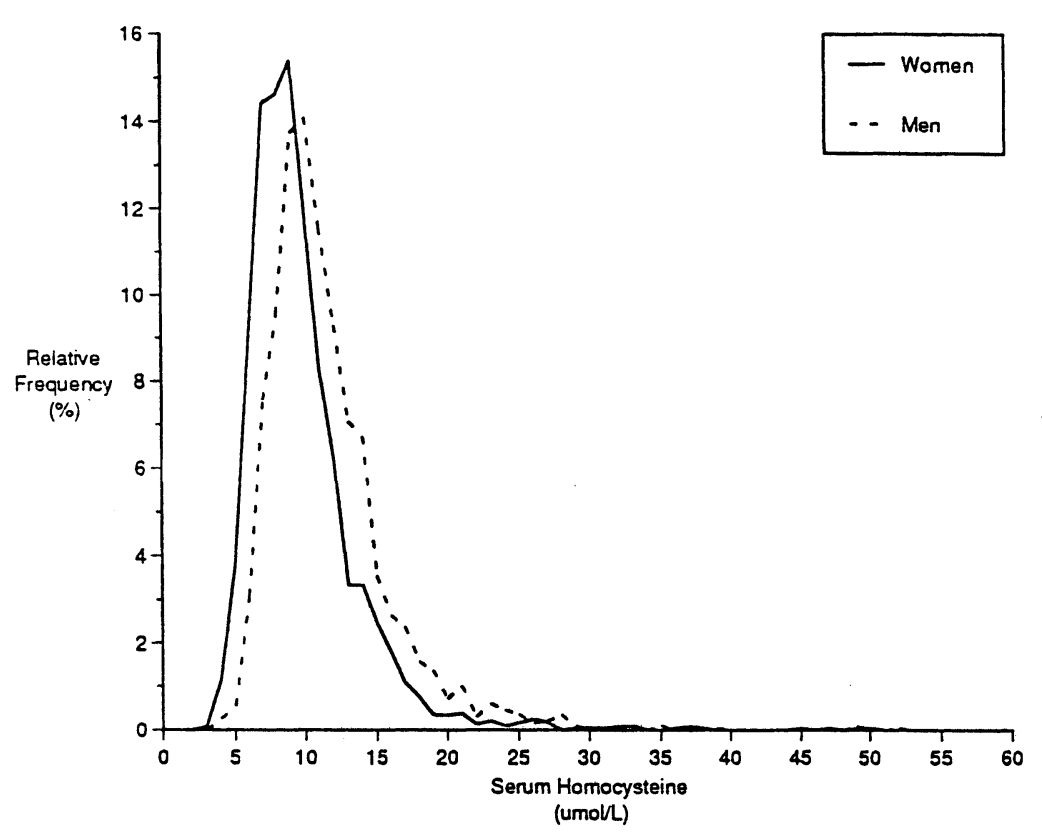

FIGURE 25-1. Distribution of serum homocysteine concentrations in 1981 men (-) and 2401 women (-), ages 12 to 102 years: Preliminary results from NHANES III. 


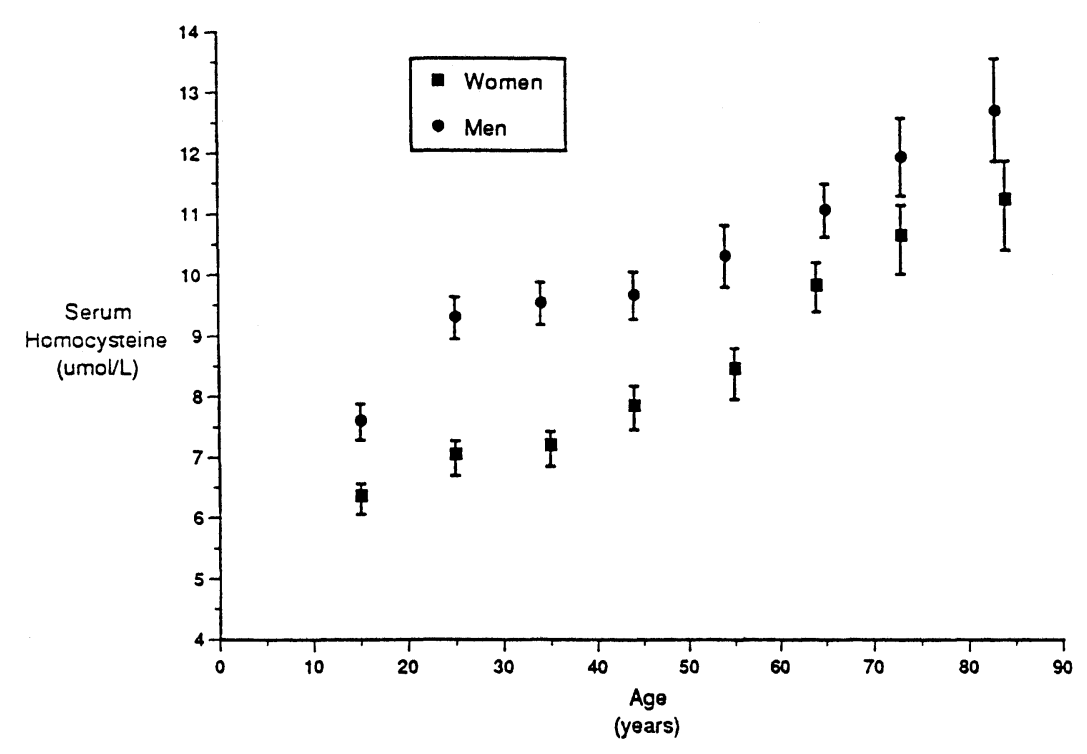

homocysteine appeared to be continuous and gradual in men except for an abrupt $23 \%$ increase between the 12-19 and 20-29 year-old age groups. This resulted in a more than 30\% higher concentration in men than in women, a difference that was largely sustained until women approached the age of 50 . At this age, concentrations in women appear to increase more rapidly with age than those in men, substantially reducing the sex-related difference in homocysteine concentrations to approximately $12 \%$ by ages $60-69$ years, a relative difference that is maintained over the next two decades of life.

Our results are consistent with observations from other large samples. The Hordaland Homocysteine Study [6] examined 7,591 men and 8,585 women ages 40-67 years with no history of vascular disease, diabetes, or hypertension. In the youngest participants (ages 40-42), homocysteine concentrations in men were $19 \%$ greater than those in women. This difference diminished to $11 \%$ in the oldest age group considered (65-67 years). Homocysteine concentrations increased $13 \%$ in men and $21 \%$ in women from age 40-42 years to age 65-67 years. Brattstrom and colleagues [7] examined a much smaller sample of 131 men and 113 women across a broader age range (35-95 years). They also observed that men had higher homocysteine concentrations than women at every age. In the youngest age groups (35-49 years), concentrations in men exceeded those in women by $11 \%$; in the oldest age group (80-95 years) these
FIGURE 25-2. Geometric mean of serum homocysteine concentrations and $95 \%$ confidence intervals by age decade in 1981 men (circles) and 2401 women (squares): Preliminary data results from NHANES III.

concentrations were $9 \%$ greater in men. In men, a steady increase in homocysteine over the age groups resulted in a $60 \%$ greater homocysteine concentration in the men ages 80-95 years compared with those who were 35-49 years old. In contrast, concentrations in women did not appear to increase until approximately age 65 years, when they demonstrated an approximately $20 \%$ increase. By age 80 , the concentrations in women, just as in men and similar to what we report here, had risen approximately $60 \%$ from the youngest age group considered.

Using data from the original Framingham cohort who were 67-96 years of age, we previously reported [8] that homocysteine concentrations were $10 \%$ higher in men than in women under age 75 years of age, and that the sex difference was reduced in the older age groups. We also reported that homocysteine concentrations continued to increase across this range of older ages. We observed a 20\% increase in homocysteine in this older cohort even across the fairly narrow (29-year) age range. Much of this increase was seen for those subjects over age 80 . We have also noted very similar age and sex relations with homocysteine in the Framingham Offspring cohort, in which we have collected data on men and women 
ages $26-83$ years (unpublished observations), and in these preliminary NHANES III data.

Although the analyses of NHANES III homocysteine data in relation to nutrient intake, blood folate levels, and measures of vitamin $B_{12}$ status are yet to be made, and the associations with measures of renal function have not yet been performed, this rich body of information awaits analysis in association with a variety of nutrition diseases and anthropometric variables. In the absence of any of these other analyses, it would be premature to speculate on the mechanism of this increase in blood homocysteine throughout the age spectrum, or on the consistent gender difference of males always being higher.

\section{References}

1. Ueland PM, Refsum H, Brattstrom L. Plasma homocysteine and cardiovascular disease. In: Francis RBJ (ed) Atherosclerotic Cardiovascular Disease Hemostasis, and Endothelial Function. New York: Marcel Dekker, Inc., 1992, pp 183-236.

2. Boushey CJ, Beresford SAA, Omenn GS, Motulsky A. A quantitative assessment of plasma homocysteine as a risk factor for vascular disease: Probable benefits of increasing folic acid intakes. JAMA 274:1049-1057, 1995.

3. National Center for Health Statistics, Vital and Health Statistics. Plan and Operation of the Third National Health and Examination Survey, 1988-94 (Series 1, No. 32). DHHS Pub No. (PHS) 94-1308. Washington DC: U.S. Government Printing Office, 1994.

4. National Center for Health Statistics, Vital and Health Statistics. Sample Design: Third National Health and Examination Survey (Series 2, No. 113). DHHS Pub No. (PHS) 92-1387. Washington DC: U.S. Government Printing Office, 1992.

5. Araki A, Sako Y. Determination of free and total homocysteine in human plasma by high-performance liquid chromatography with fluorescence detection. J Chromatography 422:43-52, 1987.

6. Nygard O, Vollset SE, Refsum $\mathrm{H}$ et al. Plasma homocysteine and cardiovascular risk profile: The Hordaland Homocysteine Study. JAMA 274:15261533, 1995.

7. Brattstrom $L$, Lindgren $A$, Israelsson $B$, Andersson $A$, Hultberg B. Homocysteine and cysteine: Determinants of plasma levels in middle-aged and elderly subjects. $J$ Intern Med 236:633-641, 1994.

8. Selhub J, Jacques PF, Wilson PWF, Rush D, Rosenberg $\mathrm{IH}$. Vitamin status and intake as primary determinants of homocysteinemia in the elderly. JAMA 270:26932698, 1993. 